\title{
Fuzzy Logic Approach to Identify Deprivation Index in Peninsular Malaysia
}

\author{
Muhammad Azam Haris Che Amat ${ }^{1}$, Syibrah Naim ${ }^{2}$, Syerrina Zakaria ${ }^{3}$ \\ ${ }^{1,2}$ School of Computer Sciences, Universiti Sains Malaysia (USM), Pulau Pinang, Malaysia \\ ${ }^{3}$ School of Informatics and Applied Mathematics, Universiti Malaysia Terengganu (UMT), Terengganu, Malaysia
}

\begin{abstract}
Article Info
Article history:

Received Aug 23, 2018

Revised Oct 26, 2018

Accepted Nov 07, 2018

\section{Keywords:}

Basic facilities

Deprivation index

Fuzzy logic system

Inequalities index

ABSTRACT

Deprivation indices are similar to inequalities index or index of disadvantageous. It was built to measure the basic necessities in a specific study area or region. There were many indices that have been constructed in the previous study. However, since these indices had depended mostly on two factors; socio-economic conditions and geography of the study area, thus different result would be generated in different areas. The objective of this study is to construct the new index based on above factors in Peninsular Malaysia by using a fuzzy logic approach. This study employed twelve variables from different facilities condition that was obtained from Malaysia 2000 's census report. These variables were considered as input parameters in the fuzzy logic system. Data turned into linguistic variables and shaped into rules in the form of IF-ELSE conditions. After that, the centroid of area method is applied to acquire the final deprivation index for a specific district in Peninsular Malaysia. The result showed that less developed states generated lower index for examples Kelantan and Kedah while more developed states generated a higher index for examples Selangor and W.P. Kuala Lumpur.
\end{abstract}

Copyright $@ 2018$ Institute of Advanced Engineering and Science. All rights reserved.

\section{Corresponding Author:}

Muhammad Azam Haris Che Amat, School of Computer Sciences, Universiti Sains Malaysia (USM), Pulau Pinang, Malaysia.

Email: 1sntl@ccu.edu.tw

\section{INTRODUCTION}

Deprivation indices are used to measure the level of deprivation in an area. It was similar to and can be referred as an index of inequalities. These indices are widely used in many field such as public health problems, social problems and few others. Under the socio-economic term, this deprivation index can be used to measure the inequalities index for individuals, household values and area.

Several studies in the past had discussed the definition of the deprivation index, its usage, types of deprivation and so forth. Over time, there are different type of indexes that had been constructed. For example, Ontario Deprivation Index [1] was constructed and aimed to distinguish the poor people to nonpoor people as the first step of poverty measure in Canada. In 2005, [2] used the Breadline Britain Index as a poverty level indicator. By using this index, in Britain, the study of relationship of risk of murder was carried out. The other study applied Carstairs deprivation index [3]. Based on data of 2001 census, deprivation pattern had been measured by this index across Wales and England [3]. On similar note, same study location Canada was taken to create national version of deprivation index by [4]. In the study, [4] described the conceptual and methodological bases of the index and then applied it through a single example, premature mortality. The outcome index was used for health planning in Canada. A study by [5] used 2000 U.S. census to create neighborhood socioeconomic deprivation index and it aimed to examine the relation between this index and all-cause, CVD- and cancer-related mortality for men and women after adjusting for a broad array 
of important risk factors. Furthermore, it also worth to be noted that depending on the geographical and socio-economy of the study area, similar usage of indices can be applied. In [6], the study was conducted in Atlanta metropolitan area using self-constructed socioeconomic status index (SES) and contrast to [7] which were conducted in France using deprivation index (Fdep99). Both of them studied the relationship of their indices with mortality rate in their study area/region. Apart from the previous research, there are also several studies that constructed deprivation index by applying fuzzy logic approach. Researcher that applied this approach includes [8] as they introduced fuzzy measures of unidimensional and multidimensional poverty by distinguishing three levels of poverty and also the same researcher [9] as they proposed a new weighting scheme for the dimensions in multidimensional poverty indices. Fuzzy measure of the similar objective was also presented by [10]. In the research, they presented a methodology for the study of multi-dimensional aspects of poverty and deprivation. By identifying appropriate rules of aggregation of fuzzy sets and define terms to be used in fuzzy logic, they managed to come up with indicators of deprivation.

In this paper, we propose fuzzy logic system to measure the deprivation in house-hold based socioeconomy. The study area covers almost whole district in Peninsular Malaysia. This method was selected because fuzzy logic is an intelligent decision-making utilizing knowledge based-reasoning. By incorporating several verbal rules, fuzzy logic will identify the best rules and aggregate in order to determine the deprivation index of each district almost similar to research done by [10]. Besides the fuzzy logic's capability, another reason to apply fuzzy logic into this study is because the system was already incorporated in technology worldwide. A study by [11] proposed fuzzy logic decision-making modeling to be used by different business management experts due to various conventional business transaction was replaced by intelligent methodologies in decision-making processes. Fuzzy logic also presents its merits as energy conserver. The research in [12] has shown that adaptive fuzzy logic system was applied for residential energy management and similar to [13] in which advanced fuzzy logic controllers was applied in smart buildings in subtropical climates in Australia as potential energy saving.

The objectives of this paper include; i) implement fuzzy logic in the system ii) apply census 2000's data into the system iii) identify the deprivation index based on data by using fuzzy logic. The rest of the paper is organized as follows. In Section 2, we introduce data that were used during this study. Section 3 describes some definitions and methodology of fuzzy logics including the fuzzy sets, linguistic variables and phases in fuzzy logic. Section 4 discussed the detail of the proposed work. Lastly, section 5 concludes the paper.

\section{DATA CENSUS}

Malaysia is a country that has two separate regions, first one is known as Peninsular Malaysia and other is Malaysia Borneo. The latest information show that there were total of 13 states, 3 federal constitutions, 99 districts in Peninsular Malaysia and 58 districts in Malaysia Borneo. However, focus of the study were only targeted towards 82 districts in twelve states in Peninsular Malaysia due to data availability.

The data was obtained from 2000 census [14]-[15]. A survey has been conducted and a total of twelve different facilities condition in every households was taken into consideration. As a result, twelve variables were considered to develop the deprivation index in house-hold based socio-economy for each district. All the variables [16] hold the percentages value and as follows:

- $\quad$ car owned by households (car)

- motorcycle owned by households (motor)

- $\quad$ air-conditioning owned by households (aircond)

- $\quad$ washing machine owned by households (WashingMachine)

- $\quad$ fixed line telephone owned by households (FixedTel)

- television owned by households (TV)

- $\quad$ video / vcd / dvd owned by households (videoDVD)

- $\quad$ electricity 24-hours connected in households (avaiElec)

- tap water availability in households (avaiTapWater)

- $\quad$ proper toilet owned by households (proToilet)

- $\quad$ school attendance in households (SchoolAttPer)

- $\quad$ person with a tertiary education in households (TerEduPer) 


\section{METHODOLOGY}

\subsection{Fuzzy Logic System}

The concept of fuzzy logic was introduced by Zadeh [17]. It was similar to mimicking human mind. In his works, the concept of linguistic variable or "fuzzy" was introduced. Rather than using number, it is easy to express the facts or rules by using word (linguistic) form [18]. Fuzzy logic system translates to three components; fuzzy sets, linguistic variables and fuzzy rules. Each part is explained further below.

\subsubsection{Fuzzy Sets}

Figure 1 displays relationship of fuzzy sets. Based of the Figure 1, a fuzzy set a in X is defined by: $\tilde{A}=\left\{\tilde{A}=x, \mu_{A}(x)\right\}, \mathrm{x} \in X$. A fuzzy set $\tilde{A}$ in a universe of discourse $\mathrm{X}$ is characterized by a membership function $\mu \tilde{A}(\mathrm{x})$. Each element $\mathrm{x}$ in $\mathrm{X}$ is mapped to a real number in the interval [0, 1] by applying this membership function. The triangular fuzzy number (as shown in Figure 1) is commonly used in decision making due to its intuitive membership function. The most probable value of the evaluation data is produced as value of $\mathrm{x}$ at $\mathrm{m}$. The reason is because it gives the maximal grade of $\mu_{A}(x)=$ i.e., $\mu_{A}(x)=1$. Contrary to previous value, the least probable value of the evaluation data is produced as value of $x$ is at $l$ as this value gives the minimal grade of $\mu_{A(x)}$ i.e., $\mu_{A}(x)=0$. Constants $l$ represent lower bound while constant $u$ represent upper bounds of the both available area for the evaluation data. The fuzziness of the evaluation data is reflected by both of these constants. [19].

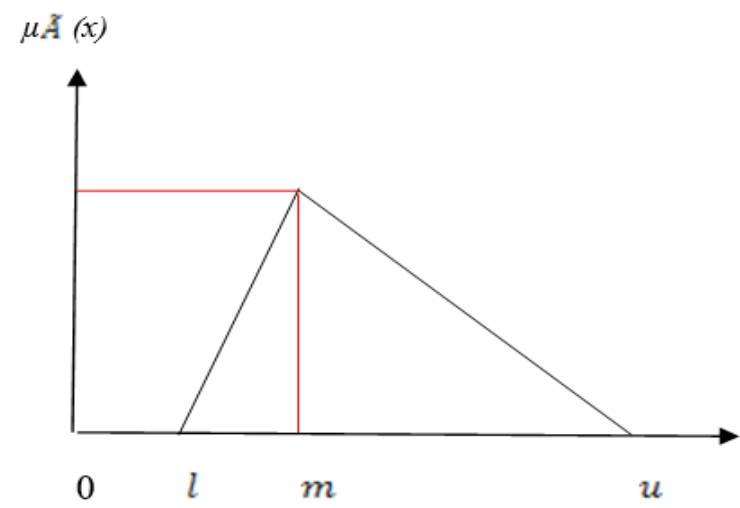

Figure 1. The triangular fuzzy number $\mathrm{A}^{\tilde{}}$

\subsubsection{Linguistic Variables}

The term refers to fuzzy partition; each fuzzy set corresponds to a linguistic concept, for instance low, average, and high. It is applied in membership function that describe the degree of belonging of variable to a fuzzy set. In this study, we define the linguistic variables for input as a poor, average and good. Variable tip is created as output and were defined in linguistic as cheap, average and generous. An example of membership function with linguistic variable is illustrated in Figure 2. Table 1 presents the linguistic concept of one variable of alternatives along with parameter of membership function. 


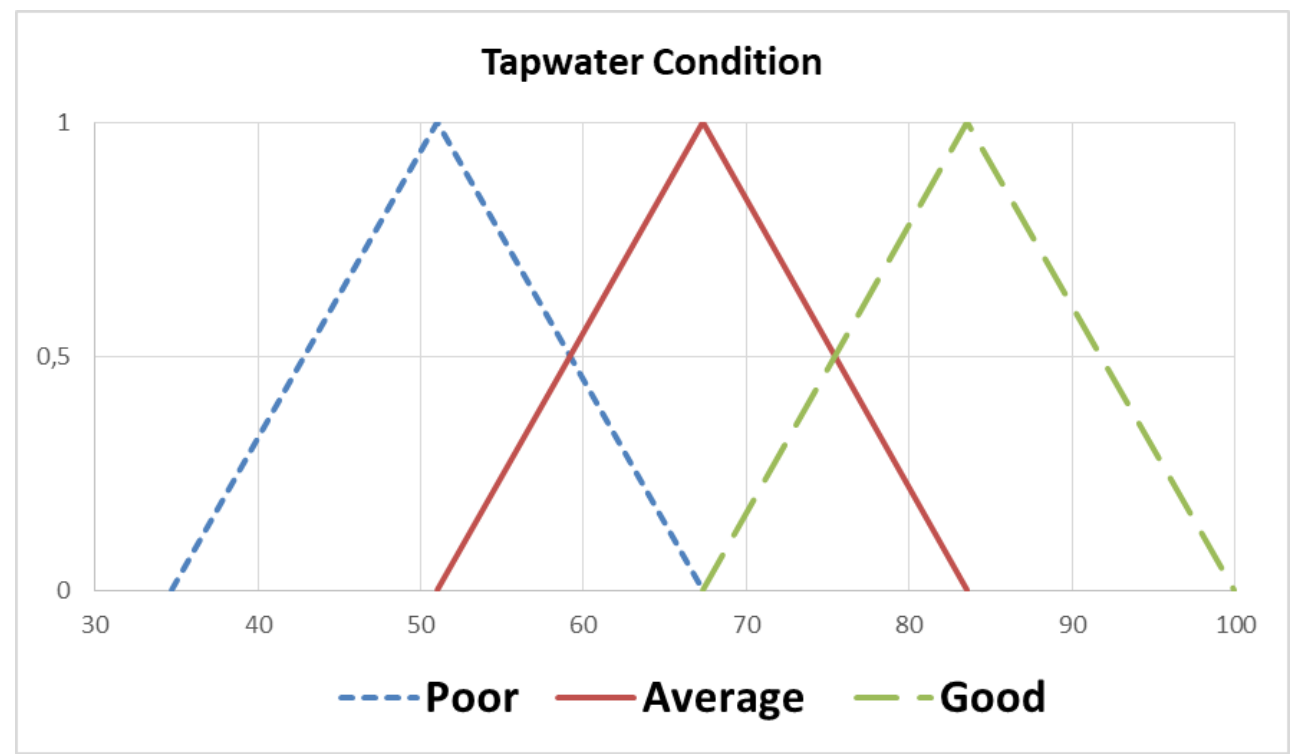

Figure 2. An example of triangular membership function of input of tap water

Table 1. Linguistic Variable Scale of Criteria of Tapwater'

\begin{tabular}{cc}
\hline Linguistic terms & Fuzzy triangular number parameter showing numbers of house-hold \\
\hline Poor & $(34.72,51,67.28)$ \\
Average & $(51,67.28,83.56)$ \\
Good & $(67.28,83.56,99.84)$ \\
\hline
\end{tabular}

\subsubsection{Fuzzy Rules}

The fuzzified data input must be processed before an actual output can be produced in fuzzy logic system. In this case, fuzzy rules are applied in the form of IF-ELSE condition. Fuzzified input data acts as premise or antecedent IF while scale of weight presented by tip acts as a conclusion THEN. Three examples out of many rules (almost 600-fired rules are generated to perform the index prediction) are defined below in linguistic concept:

a. RULE 1: IF avaiTapWater is poor AND avaiElec is poor AND proToilet is poor AND car is poor AND motor is poor AND airconditioner is poor AND WashingMachine is poor AND FixedTel is poor AND TV is few AND videoDVD is few AND SchoolAttPer is poor AND TerEduPer is poor, THEN index is poor.

b. RULE 2: IF avaiTapWater is poor AND avaiElec is good AND proToilet is good AND car is poor AND motor is poor AND aircond is poor AND WashingMachine is good AND FixedTel is average AND TV is few AND videoDVD is many AND SchoolAttPer is average AND TerEduPer is average THEN index is average.

c. RULE 3: IF avaiTapWater is good AND avaiElec is good AND proToilet is good AND car is good AND motor is good AND aircond is good AND WashingMachine is good AND FixedTel is poor AND TV is good AND videoDVD is average AND SchoolAttPer is good AND TerEduPer is average THEN index is good.

\subsubsection{Fuzzy Logic Phase}

For the fuzzy logic to works, it will have to undergone three phases; Fuzzification, Inference rules and Defuzzification. The flow of fuzzy logic was briefly explained in the Figure 3. 


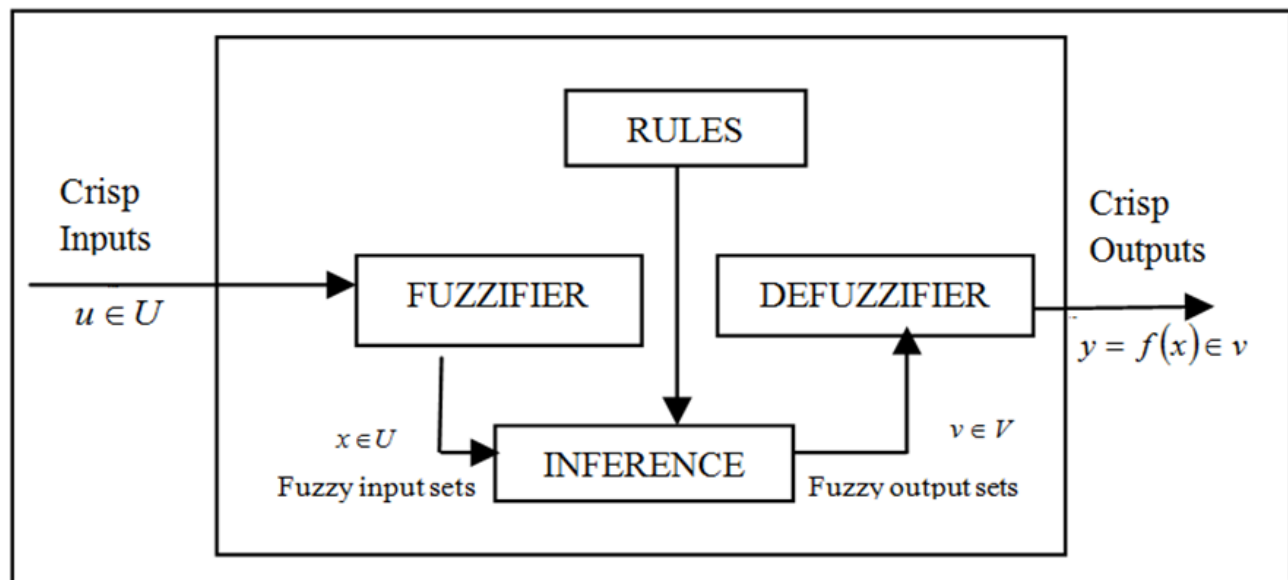

Figure 3. Block diagram of fuzzy logic

In this study, the data census 2000 is applied. The first fuzzification phases converted the input that is a crisp (data census) into numerical value, and then into qualifying linguistic variables (with interval always from 0 to 1). In this case, the linguistic variables can be classified as antecedent. The process was performed using membership function. In this study, the membership function was created using a formula that also known as triangular-shaped membership function refer to Figure 1. It was defined as (1):

$$
f(x ; a, b, c)=\left(\min \left(\frac{x-a}{b-a}, \frac{c-x}{c-b}\right), 0\right)
$$

where $\mathrm{x}$, percentage of target variable observed, while $\mathrm{a}, \mathrm{b}$, and c represented each parameter of triangularshaped membership function. The formula was applied after the input has been fuzzified.

A fuzzy AND operation and min(minimum) was applied if the antecedent of a rule has more than one part to represent the result of the antecedent. Next, the consequent was created by applying implication method to the output of fuzzified value. The rule fired, need to be determined for this purpose. Therefore, fired membership degree from previous subsection was applied. The same method AND operator was applied in order to truncates and scales the output of fuzzy sets. Identically, the rules of antecedent and consequent can also be represented in the form of IF-ELSE condition as stated in previous subsection. After all the previous process, the fuzzified output undergone aggregation that combines all output of each rules in the fuzzy sets into a single fuzzy set.

Lastly, the aggregate output fuzzy set was defuzzified to obtain a single output value from the range of output values from a fuzzy set. This phase was done using centroid of area technique (COA). The formula of COA represent in (2):

$$
g=\frac{\Sigma \text { a.c }}{\Sigma a}
$$

where a represented the antecedent and $\mathrm{c}$, the consequent. This technique yield final fuzzy outputs that was converted back to normal output so the deprivation index of a certain district can be identified.

\section{RESULT AND DISCUSSION}

The outcomes of this study were presented in two tables. Each outcome represented the deprivation index in each district in Peninsular Malaysia. In order to find the ranking of deprivation index, all the variables from the twelve different facilities condition was combined and used as input data in the fuzzy logic. As discussed in the methodology section, antecedent acted as a premise while consequent acted as a conclusion of the rule. Total number of rules were almost 600. The estimate deprivation index was calculated by applying both values using the formula below for example, in Batu Pahat District and Sik District:

$$
\text { Batu Pahat: } \begin{aligned}
g & =\frac{\Sigma \text { a.c }}{\Sigma a},=0.7668(0.0)+\ldots . .+0.2391(0.5)+\ldots .+0.551(1.0) \\
& =0.6 .
\end{aligned}
$$


Sik

$$
\begin{aligned}
: g & =\frac{\Sigma \text { a.c }}{\Sigma a}, \quad=0.5537(0.0)+\ldots . .+0.4463(0.5)+\ldots .+0.1784(1.0) \\
& =0.38
\end{aligned}
$$

The larger the index value indicate that the 12 variables necessities were beyond the basic needs in the district and vice versa. Therefore, when comparing Sik to Ulu Langat, its shows that Ulu Langat was more developed and has better necessities of life compared to Sik. Ten districts each with smallest index of deprivation was displayed in Table 2 while Table 3 displays the ten districts each with highest index of deprivation. Overall, it has been observed that less developed states produced lower index such as Kelantan (Gua Musang, Kuala Kerai, Pasir Mas, Tanah Merah) in the first rank followed by Perak (Ulu Perak, Cameron Highland) and then Pahang (Lipis, Pekan) while more developed states produced higher index such as Selangor (Petaling) in the first rank followed by W.P. Kuala Lumpur and then Melaka (Melaka Tengah). The full index list for all targeted districts can be referred in the Appendix.

Table 2. Ten Districts with Smallest Index

\begin{tabular}{cc}
\hline District & Index \\
\hline Kuala Krai & 0.35 \\
Gua Musang & 0.35 \\
Sik & 0.38 \\
Ulu Perak & 0.39 \\
Lipis & 0.40 \\
Pasir Mas & 0.43 \\
Tanah Merah & 0.44 \\
Pekan & 0.44 \\
Cameron Highlands & 0.44 \\
Setiu & 0.45 \\
\hline
\end{tabular}

Table 3. Ten Districts with Higher Index

\begin{tabular}{cc}
\hline District & Index \\
\hline Petaling & 0.83 \\
W.P. Kuala Lumpur & 0.76 \\
Melaka Tengah & 0.69 \\
Ulu Langat & 0.67 \\
Sabak Bernam & 0.65 \\
Kubang Pasu & 0.65 \\
Kota Setar & 0.64 \\
Timur Laut & 0.64 \\
Manjung (Dinding) & 0.64 \\
Johor Bahru & 0.63 \\
\hline
\end{tabular}

\section{CONCLUSION}

Deprivation index can be referred as inequalities index. Under the socio-economic term, this deprivation index can be used to measure the inequalities index for individuals, household values and area. Different index for different purpose has been constructed by the previous study for example Ontario Deprivation Index, Breadline Britain Index, Carstair Deprivation Index, Socioeconomic Status Index and other. All of these indices are constructed by considering the two factors that is socio-economic and geography of the study area. This study has built the deprivation index by means of fuzzy logic approach. The study area chosen was 82 districts in twelve states of Peninsular Malaysia.

The index was constructed by three phases in fuzzy logic namely fuzzification, inference rules and defuzzification. The data used were twelve variables based on twelve different facilities condition. Fuzzification turn these data into linguistic variable (interval from 0 to 1). The linguistic variable was then passed to inference rules phases. By using a membership function, several rules in the form of IF-ELSE conditions were constructed. All of these rules were then aggregate and then send to the final phase defuzzification so that fuzzy logic can yield the final output which is deprivation index of each district. Overall, it has been observed that less developed states produced lower index while more developed states produced higher index.

The result obtained in this study are very useful in many ways. For example, authorities can devise a countermeasure again the deprivation on a specific area based on this index. Countermeasure include the reducing rate of crime, improving health and living environment, increase rate of employment and others.

\section{ACKNOWLEDGEMENTS}

Short Term Grant, Universiti Sains Malaysia, under account number 304/PKOMP/6315084, supported this work.

\section{REFERENCES}

[1] Richard M, Michael M, Michael O. Developing a Deprivation Index: The Research Process. Toronto: Daily Bread Food Bank and the Caledon Institute of Social Policy. 2009.

[2] Mary S, Helena T, Danny D. Increasing Inequalities in Risk of Murder in Britain: Trends in the Demographic and Spatial Distribution of Murder, 1981-2000. Health \& Place, 2005; vol.11, pp. 45-54.

[3] Oliver M. Allan B. Measuring Deprivation in England and Wales using 2001 Carstairs Scores. Health Statistics Quarterly 31. Office for National Statistics. 2006. 
[4] Pampalon R. Hamel D. Gamache P. Raymond G. A deprivation index for health planning in Canada, Chronic diseases in Canada. 2009; vol. 29, pp. 178-191.

[5] Major JM, Doubeni CA, Freedman ND, Park Y, Lian M. Hollenbeck AR, Schatzkin A, Graubard BI, Sinha R. Neighborhood Socioeconomic Deprivation and Mortality: NIH-AARP Diet and Health Study. PLoS ONE 5(11): e15538, 2010, doi: 10.1371/journal.pone.0015538, in press.

[6] James BH, and Lo CP. The Geography of Mortality in the Atlanta Metropolitan. Computer, Environment \& Urban System. 2008; vol. 32, pp. 149-164.

[7] Rey G, Jougla E, Fouillet A, Hémon D. Ecological Association Between a Deprivation Index and Mortality in France over the Period 1997 - 2001: Variations with Spatial Scale, Degree of Urbanicity, Age, Gender and Cause of Death. BMC Public Health. 2009; vol. 9(33).

[8] Besma B. New fuzzy indices of poverty by distinguishing three levels of poverty. Research in Economics. 2011; vol. 65(3), pp. 221-231.

[9] Besma B. New weighting scheme for the dimensions in multidimensional poverty indices. Economic Letters, 2012; vol. 116(3), pp. 304-307.

[10] Gianni B, Vijay V. Fuzzy Measures of the Incidence of Relative Poverty and Deprivation: A Multi-Dimensional Perspective, in Statistical Methods and Applications. 2008; vol. 17(2), pp. 225-250.

[11] Şen. Z. Intelligent business decision-making research with innovative fuzzy logic system. Int. J. Research, Innovation and Commercialisation. 2017; vol. 1, pp. 93-109.

[12] Azim K, Siamak A. An adaptive fuzzy logic system for residential energy management in smart grid environments. Applied Energy. 2017; vol. 186, pp. 68-81.

[13] Yazeed YG, Rasul MG, Khan M.M.K. Potential of Saving Energy Using Advanced Fuzzy Logic Controllers in Smart Buildings in Subtropical Climates in Australia. ${ }^{6}$ th International Conference on Applied Energy ICAE2014. Energy Procedia. 2014; vol. 61, pp. 290-293.

[14] Malaysia. Population Sprinkles and Characteristics of Demographic Principles: Transvestites of Malaysian Population and Housing (in Malaysia). 2000. Department of Statistics Malaysia. 2000.

[15] Malaysia. Am Sissy Population and Housing Report: Sissy of Malaysian Population and Housing (in Malaysia) 2000. Department of Statistics Malaysia. 2005.

[16] Abdul RN, Zakaria S. The Household-Based Socio-Economic Index for Every District in Peninsular Malaysia. World Academy of Science, Engineering and Technology. International Journal of Mathematical, Computational, Physical, Electrical and Computer Engineering, 2012; vol. 6, pp. 1389-1395.

[17] Zadeh L. A. Information and Control. 1965. vol. 8, pp. 338-353.

[18] Vamsi MP. Fuzzy logic controller for an autonomous mobile robot. 2002.

[19] Yaafar A, Naim S, Che Taib CMI. Evaluating Criteria of Port Dock for Ship Berthing Using Fuzzy TOPSIS Approach. International Conference And Workshop On Mathematical Analysis 2016 (ICWOMA 2016). Accepted for Oral Presentation, August 2-4, 2016, Langkawi, Malaysia.

\section{Appendix}

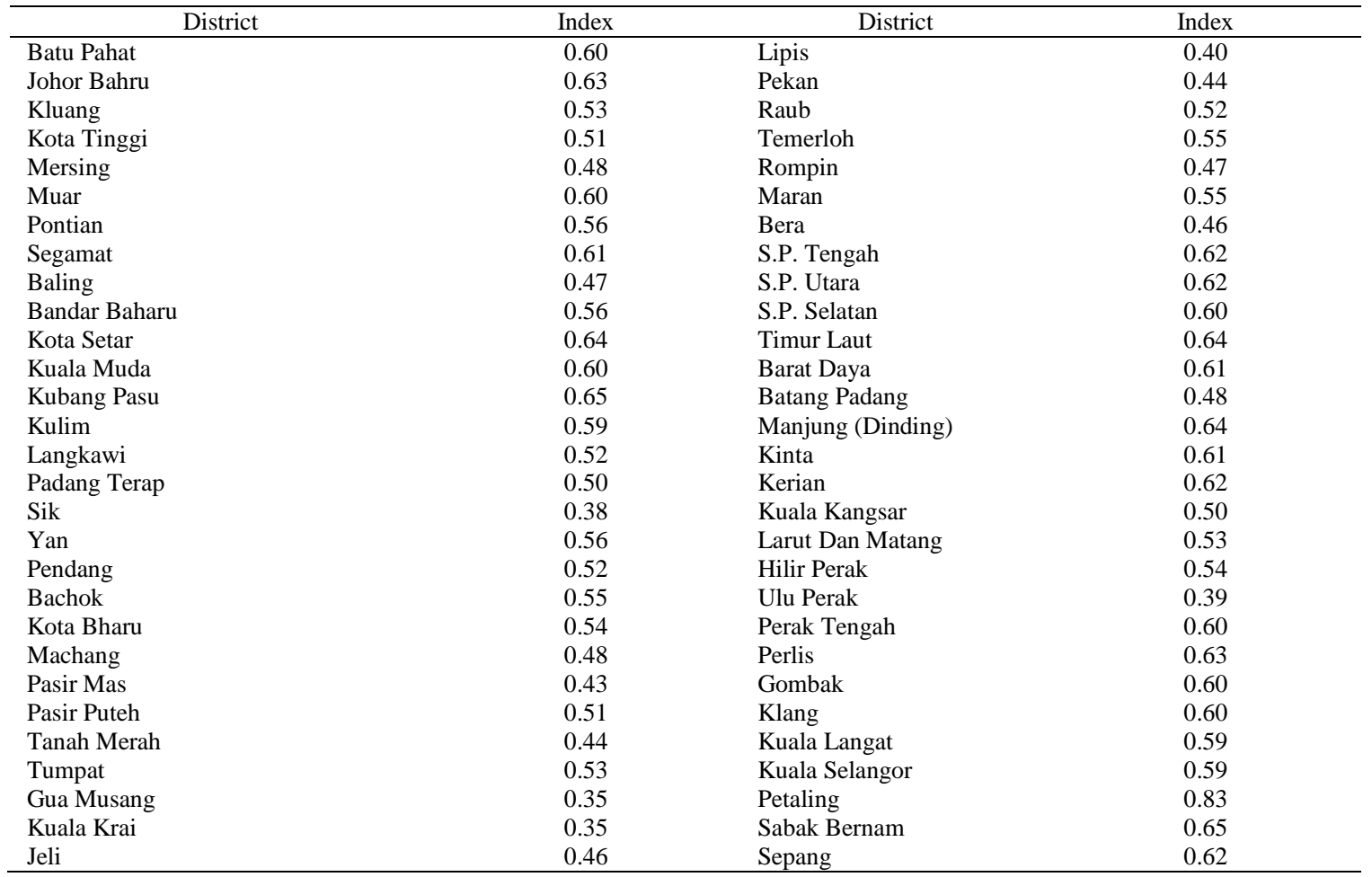

Fuzzy Logic Approach to Identify Deprivation Index in... (Muhammad Azam Haris Che Amat) 


\begin{tabular}{llll}
\hline & & & \\
\hline Alor Gajah & 0.63 & Ulu Langat & 0.67 \\
Jasin & 0.63 & Ulu Selangor & 0.60 \\
Melaka Tengah & 0.69 & Besut & 0.46 \\
Jelebu & 0.53 & Dungun & 0.58 \\
Kuala Pilah & 0.61 & Kemaman & 0.55 \\
Port Dickson & 0.58 & Kuala Terengganu & 0.58 \\
Rembau & 0.57 & Marang & 0.57 \\
Seremban & 0.62 & Hulu Terengganu & 0.52 \\
Tampin & 0.63 & Setiu & 0.45 \\
Jempol & 0.57 & W.P. Kuala Lumpur & 0.76 \\
Bentong & 0.53 & & \\
Cameron Highlands & 0.44 & & \\
Jerantut & 0.47 & & \\
Kuantan & 0.56 & & \\
\hline
\end{tabular}

